Diabetologia (1995) 38: 221-226

\title{
Diabetic nephropathy: a risk factor for diabetes mellitus in offspring
}

\author{
D.R. McCance ${ }^{1,2}$, R. L. Hanson ${ }^{1}$, D.J. Pettitt ${ }^{1}$, L. T.H. Jacobsson ${ }^{1,3}$, P.H. Bennett ${ }^{1}$, D. T. Bishop ${ }^{4}$, \\ W. C. Knowler ${ }^{1}$ \\ ${ }^{1}$ Diabetes and Arthritis Epidemiology Section, Phoenix Epidemiology and Clinical Research Branch, National Institute \\ of Diabetes and Digestive and Kidney Diseases, Phoenix, Arizona, USA \\ ${ }^{2}$ Sir George E. Clark Metabolic Unit, Royal Victoria Hospital, Belfast, Northern Ireland, UK \\ ${ }^{3}$ Department of Rheumatology, General Hospital, Malmö, Sweden \\ ${ }^{4}$ Imperial Cancer Research Fund, Leeds, UK
}

Summary Both non-insulin-dependent diabetes mellitus and diabetic nephropathy show familial aggregation. If diabetes and renal disease have independent determinants (genetic or otherwise), offspring of parents with diabetic renal disease should have a similar risk of diabetes to those offspring of parents with diabetes alone. To test this hypothesis, the prevalence of diabetes was examined in a population-based pedigree study in Pima Indian offspring of three mutually exclusive parental types: 1) diabetic with renal disease, 2) diabetic, but without renal disease and 3) non-diabetic. Among offspring of one diabetic parent and one non-diabetic parent $(n=320)$ the prevalence of diabetes at ages 15-24 years and 25-34 years was $0 \%$ and $11 \%$, respectively if the diabetic parent did not have renal disease compared with $6 \%$ and $28 \%$ respectively if the diabetic parent did have renal disease. Corresponding rates for offspring of two diabetic parents $(n=121)$ were $10 \%$ and $17 \%$, respectively if neither parent had renal disease compared with $30 \%$ and $50 \%$, respectively if one parent did have renal disease. The presence of renal disease in a parent with diabetes relative to diabetes alone was associated with 2.5 times the odds of diabetes $(95 \%$ confidence interval 1.4-4.3) in the offspring controlled for age, age at onset of parental diabetes and diabetes in the other parent using logistic regression. These findings provide support for parental diabetic renal disease, independent of age at onset of parental diabetes, conferring an increased risk for diabetes in the offspring. The results are compatible with the hypothesis that the susceptibility to renal disease in the parents and to diabetes in the offspring are due to shared familial environmental factors or to the same gene or set of genes. [Diabetologia (1995) 38: 221-226]

Key words Familial aggregation, diabetes mellitus, nephropathy.
Familial aggregation of non-insulin-dependent diabetes mellitus (NIDDM) has been observed in several populations and has been interpreted as evidence for a genetic component for the disease [1-6]. More recently, aggregation of diabetic renal disease has been reported among families in whom the prevalence of diabetes is high [7-8]. It is not established, however, whether these observations re-

Received: 21 March 1994 and in revised form: 24 August 1994

Corresponding author: Dr. D. R. McCance, Sir George E.Clark Metabolic Unit, Royal Victoria Hospital, Grosvenor Road, Belfast, BT12 6BA, Northern Ireland, UK

Abbreviations: NIDDM, Non-insulin-dependent diabetes mellitus; ESRD, end-stage renal disease. flect independent phenomena. On the one hand, if there are independent determinants of susceptibility to nephropathy and to diabetes, offspring of parents with diabetic renal disease would have a similar risk of developing diabetes to those whose parents have diabetes alone. Alternatively, the same factors might be responsible for the familial aggregation of NIDDM and nephropathy. In this case one might anticipate a dosage effect, with the combination of parental diabetes and renal disease resulting in a greater susceptibility to diabetes than the presence of parental diabetes alone, which would be manifest by a higher prevalence of diabetes in the offspring.

The present study examines the prevalence of diabetes in offspring in relation to parental diabetes 
with or without nephropathy in Pima Indians, a population in which familial aggregation of both diabetes and nephropathy has been demonstrated previously $[5,6,8-11]$.

\section{Subjects and methods}

The subjects are participants in a longitudinal study of diabetes which has been conducted among Pima Indian residents of the Gila River Indian Community of Arizona since 1965 [12-13]. Familial data are based on examination of all subjects rather than reliance on family history. Residents of the community over the age of 5 years are asked, every 2 years, to participate in a standardized examination which includes the determination of venous plasma glucose $2 \mathrm{~h}$ after the ingestion of $75 \mathrm{~g}$ of carbohydrate (Glucola, Ames Co., Elkhart, Ind., or Dexcola, Custom Laboratories, Baltimore, Md. USA), Diabetes was diagnosed according to World Health Organization criteria for epidemiologic studies if the post-load plasma glucose concentration was at least $11.1 \mathrm{mmol} / \mathrm{l}(200 \mathrm{mg} / \mathrm{dl})$ [14] at a survey examination, or if a casual plasma glucose greater than or equal to $11.1 \mathrm{mmol} / \mathrm{l}$ was observed in the course of routine medical care.

Subjects were asked to void before ingesting the carbohydrate, and a urine specimen was collected $2 \mathrm{~h}$ later. This urine specimen was tested for protein by dipstick (Labstix, Ames Co.), and urine containing a trace or more of protein was tested quantitatively for protein using a precipitation technique [15] and for creatinine using an automated alkaline picrate method [16]. Two definitions of renal disease were used: (1) end stage renal disease (ESRD): defined either by the need for dialysis or by a serum creatinine greater than $442 \mu \mathrm{mol} / 1$ ( $\geq 5 \mathrm{mg} / \mathrm{dl}$ ) and (2) proteinuria: defined as a single protein to urine creatinine ratio $(\mathrm{p} / \mathrm{c})$ of greater than or equal to $1 \mathrm{~g} / \mathrm{g}$ (113 $\mathrm{mg}$ protein $/ \mathrm{mmol}$ creatinine) which corresponds to a urine protein excretion of approximately $1 \mathrm{~g} / 24 \mathrm{~h}[17,18]$. The ascertainment of ESRD in this population up to June 1986 has been described previously [19]. These records were updated to December 1992. In each subject with ESRD, the clinical records were reviewed to determine the cause of the renal failure. ESRD was attributed to diabetic nephropathy if the subject had diabetes and ESRD with chronic persistent proteinuria in the absence of other demonstrable causes of renal disease. Renal failure in the Pima Indians occurs almost exclusively in the context of diabetes and then, in over $97 \%$ of subjects, is due to diabetic nephropathy [19].

The analysis was restricted to offspring of parents who were of at least half Indian heritage and both of whose parents could be categorized into one of three mutually exclusive parental types (Table 1): (a) diabetic with renal disease (DR) proteinuria or ESRD as defined above, (b) diabetic without renal disease $(D)$ - diabetes duration at least 15 years and $p / c$ less than 0.5 (c) non-diabetic (ND) - age at least 45 years without diabetes and $\mathrm{p} / \mathrm{c}$ under 0.5 . With the exception of the ESRD group, these categories were defined at the most recent biennial examination. Offspring of parents with intermediate protein excretion ( $\mathrm{p} / \mathrm{c}$ between 0.5 and $1.0 \mathrm{~g} / \mathrm{g}$ ) were excluded to minimise misclassification. Although the prevalence of renal disease in diabetes increases with disease duration, subjects who had not developed nephropathy within 15 years of diabetes onset were considered to represent a group of subjects at relatively low risk of this complication. As the prevalence of diabetes in offspring did not vary by sex of the affected parent, the parental variables were defined without regard to sex.
Table 1. Characteristics of parents

\begin{tabular}{lrlll}
\hline Parents & $n$ & $\begin{array}{l}\% \\
\text { Male }\end{array}$ & $\begin{array}{l}\text { Mean age at last } \\
\text { examination (years) }\end{array}$ & $\begin{array}{l}\text { Mean age at dia- } \\
\text { betes onset (years) }\end{array}$ \\
\hline DR & 133 & 41 & $56.8 \pm 11.2$ & $40.4 \pm 10.6$ \\
D & 78 & 39 & $60.7 \pm 10.3$ & $40.6 \pm 10.9$ \\
ND & 195 & 61 & $59.6 \pm 10.5$ & \\
Total & 406 & 50 & $58.9 \pm 10.8$ & \\
\hline
\end{tabular}

Mean \pm SD

DR, Diabetes with renal disease: ESRD or urine protein/creatinine $[\mathrm{p} / \mathrm{c}]$ ratio $\geq 1 \mathrm{~g} / \mathrm{g} ; \mathrm{D}$, diabetes with duration $\geq 15$ years and urine protein/creatinine $[\mathrm{p} / \mathrm{c}]$ ratio $<0.5 \mathrm{~g} / \mathrm{g} ; \mathrm{ND}$, non-diabetic, age $\geq 45$ years and urine protein creatinine ratio $[\mathrm{p} / \mathrm{c}]$ $<0.5 \mathrm{~g} / \mathrm{g}$

We were unable to determine if subjects with proteinuria who did not develop ESRD had a non-diabetic cause contributing to their proteinuria. However, we excluded from the analysis families of 12 subjects with ESRD and a documented histological cause other than or in addition to that of diabetes for their renal disease (nine with glomerulonephritis, and one each with post-infectious glomerulonephritis, hypertensive and obstructive nephropathy). This group was too small to examine in terms of the risk presented for diabetes in the offspring especially in light of the rarity of renal failure in nondiabetic Pima Indians.

\section{Statistical analysis}

The prevalence of diabetes in offspring was examined by parental status. As the number of offspring in several parental categories was small, these were grouped into offspring in whom one or more of the parents had diabetic renal disease (comprising parental combinations of $[\mathrm{DR} \times \mathrm{DR}],[\mathrm{DR} \times \mathrm{D}]$ and $[\mathrm{DR} \times \mathrm{ND}]$, offspring of one or more diabetic parents who did not have renal disease (comprising parental combinations of $[\mathrm{D} \times \mathrm{D}]$ and $[\mathrm{D} \times \mathrm{ND}])$ and offspring of two non-diabetic parents $[\mathrm{ND} \times \mathrm{ND}]$.

The potential confounding effects of age at onset of parental diabetes was examined using logistic regression. For this analysis, offspring were restricted to those of [DR $\times N D]$ vs $[\mathrm{D} \times \mathrm{ND}]$ and $[\mathrm{DR} \times \mathrm{D}]$ vs $[\mathrm{D} \times \mathrm{D}]$ parental combinations as these were considered to be the most useful for determining a possible additional effect of diabetic renal disease to that of diabetes alone. Covariates included age and sex of the offspring and age at onset of parental diabetes. The latter was defined either as that of the diabetic parent, if only one parent had diabetes $([\mathrm{D} \times \mathrm{ND}]$ or $[\mathrm{DR} \times \mathrm{ND}])$, or the younger of the two onset ages if both parents had diabetes $([\mathrm{D} \times \mathrm{D}]$ or $[\mathrm{DR} \times \mathrm{D}])$. Two indicator variables were used to represent the effect of diabetic renal disease and of diabetes per se. The first indicator variable was given a value of 1 if either parent had diabetic renal disease and 0 if diabetes alone. The second indicator variable was assigned a value of 1 if both parents had diabetes and 0 otherwise. Since this analysis was restricted to those with at least one diabetic parent, the first indicator variable thus served as an indication of the effect of renal disease in a diabetic parent compared with that of diabetes alone and the second indicator variable represented the presence or absence of diabetes in the other parent. Odds ratios were calculated as described by Kleinbaum et al. [20].

The possible effect of parental status on the degree of hyperglycaemia as a continuous variable (rather than diabetes as a dichotomy) in the offspring was assessed by examining 
Table 2. Prevalence of diabetes in offspring by combination of parental variables and age of offspring

\begin{tabular}{|c|c|c|c|c|c|c|}
\hline \multirow[t]{3}{*}{ Parental combination } & \multicolumn{6}{|c|}{ Age of offspring (years) } \\
\hline & \multicolumn{2}{|c|}{ a $15-24$} & \multicolumn{2}{|l|}{$25-34$} & \multicolumn{2}{|l|}{ 35-up } \\
\hline & No. & Rate & No. & Rate & No. & Rate \\
\hline $\mathrm{DR} \times \mathrm{D}$ & $6 / 20$ & $30.0 \%$ & $14 / 28$ & $50.0 \%$ & $22 / 32$ & $68.8 \%$ \\
\hline $\mathrm{DR} \times \mathrm{ND}$ & $3 / 49$ & $6.1 \%$ & $20 / 72$ & $27.8 \%$ & $40 / 61$ & $65.6 \%$ \\
\hline $\mathrm{D} \times \mathrm{D}$ & $1 / 10$ & $10.0 \%$ & $2 / 12$ & $16.7 \%$ & $1 / 2$ & $50.0 \%$ \\
\hline
\end{tabular}

a Data are confined to offspring aged $\geq 15$ years, as only two subjects (both of $[\mathrm{DR} \times \mathrm{D}]$ parents) developed diabetes below this age. For definition of parental categories see Footnote to Table 1.

the above covariates in a linear regression model with the log of the maximum recorded $2-\mathrm{h}$ plasma glucose in the offspring as the dependent variable. Conventional regression analysis assumes independence of individual observations which is not the case for offspring within a nuclear family. Because of such intrasibship correlations, the confidence intervals are probably too narrow and the $p$-values too small from a conventional regression model. Thus, conditional linear regression using the same covariates as the conventional model but accounting for the intrasibship correlations was performed using the REGC program of the Statistical Analysis for Genetic Epidemiology (SAGE) package [21].

The adjusted geometric mean of maximum 2-h plasma glucose values for offspring aged 20 years for each of the four parental combinations, by age at onset of parental diabetes, was estimated from the $\beta$ coefficients of the conditional linear regression model.

\section{Results}

The prevalence of diabetes in offspring aged 15 years and over by age group and parental types, is shown in Table 2, and for grouped parental categories in Figure 1 . Below 25 years of age, diabetes occurred in only one offspring of whom neither diabetic parent had renal disease. The presence of parental diabetic renal disease was associated with a higher prevalence of diabetes in offspring. In subjects aged 15-24 years, the prevalence of diabetes in offspring of one or more parents with diabetic renal disease $([\mathrm{DR} \times \mathrm{DR}]$, $[\mathrm{DR} \times \mathrm{D}]$ and $[\mathrm{DR} \times \mathrm{ND}])$ was $15.2 \%$ compared with $2.1 \%$ among offspring of one or more parents with diabetes but no renal disease $[\mathrm{D} \times \mathrm{D}]$ and [D $\times$ ND]). Similarly, in subjects aged $25-34$ years, corresponding figures were $36.8 \%$ and $12.5 \%$, respectively. In subjects older than 35 years, while the presence of one or more parents with renal disease conferred the highest risk for diabetes in the offspring, there was a high prevalence $(40 \%)$ of diabetes even in offspring of two non-diabetic parents (Fig. 1).

Table 3 shows the odds ratios from a logistic model used to control for the covariates. Diabetes in the offspring was associated with current age of the offspring and a younger age at onset of parental dia-

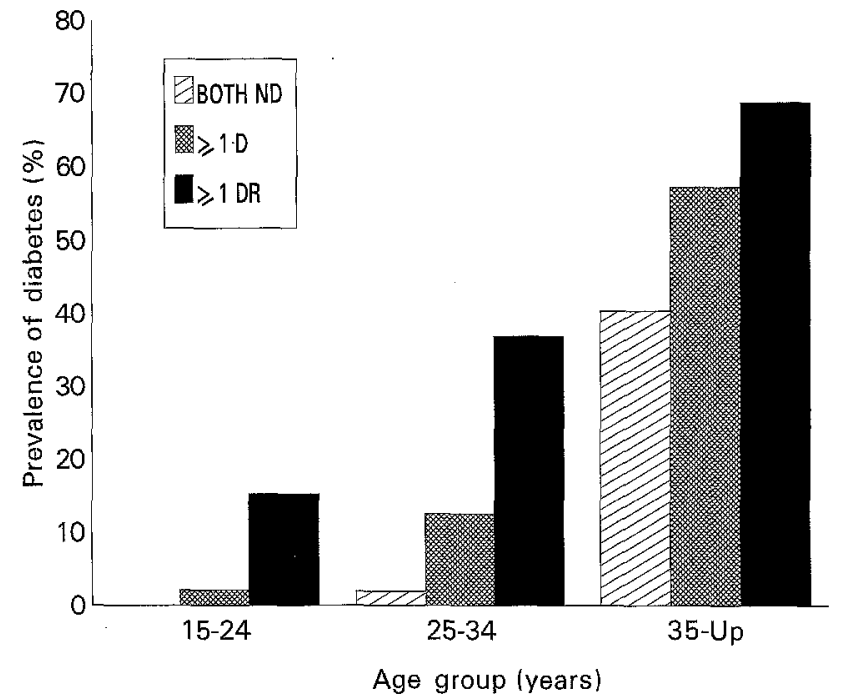

Fig. 1. Prevalence of diabetes in offspring by combination of parental categories: Both ND- both parents non-diabetic; $\geq 1$ $\mathrm{D}$ (both parents diabetic without renal disease (D) or one parent $\mathrm{D}$ and the other ND; $\geq 1 \mathrm{DR}$ (both parents diabetic with renal disease $(D R)$ or one parent $D R$ and the other $D$ or ND)). For definition of parental categories see Footnote to Table 1

betes. Controlled for these variables, the odds for diabetes in the offspring of a parent with renal disease relative to the offspring of a parent with diabetes alone was 2.47 (95\% C.I. 1.41-4.32).

Because the diagnosis of diabetes is based on a dichotomy of a continuous variable, $2 \mathrm{~h}$ plasma glucose, the association of parental diabetic renal disease with the glucose concentration in the offspring was also examined by linear regression. The "age" of the offspring was considered as that which coincided with the maximum glucose value. Controlled for age of the offspring, diabetes in the other parent and age at onset parental diabetes, (Table 4), left, the presence of DR in either parent was significantly associated with the maximum 2-h plasma glucose in the offspring $(p=0.0035)$.

The effect of parental renal disease on the plasma glucose in the offspring was also examined using a 
Table 3. Multiple logistic regression model for diabetes in offspring of $[D R \times D],[D R \times N D],[D \times D]$ and $[D \times N D]$ parental combinations. Dependent variable: diabetes in offspring

\begin{tabular}{lllll}
\hline Variable & Parameter estimate & Odds ratio & $95 \%$ C.I. & $p$ value \\
\hline Age of offspring (per 10 years) & 1.4220 & 4.15 & $3.08-5.57$ & 0.0001 \\
DR in first parent (DR vs D) & 0.9034 & 2.47 & $1.41-4.32$ & 0.0015 \\
D in 2nd parent (D vs ND) & 0.5007 & 1.65 & $0.93-2.94$ & 0.0899 \\
Age at onset of parental diabetes (per year) & -0.0544 & 0.95 & $0.92-0.98$ & 0.0003 \\
\hline
\end{tabular}

$95 \%$ Confidence interval (C.I.)

$\mathrm{DR}$, diabetic with renal disease; $\mathrm{D}$, diabetes without renal dis-

ease; Age, at onset of diabetes in diabetic parent (or younger

of the two ages of onset if both parents diabetic). Sex was not significant and therefore was not included as a covariate. For definition of terms see text

Table 4. Conventional (left) and conditional (right) multiple linear regression models in offspring of $[D R \times D]$, $[D R \times N D]$, $[\mathrm{D} \times \mathrm{D}]$ and $[\mathrm{D} \times \mathrm{ND}]$ parental combinations. Dependent variable: $\log _{10}$ (maximum 2-h plasma glucose in mmol/l) in offspring

\begin{tabular}{|c|c|c|c|c|}
\hline \multirow[t]{2}{*}{ Variable } & \multicolumn{2}{|l|}{ Conventional } & \multicolumn{2}{|l|}{ Conditional } \\
\hline & $\beta$ coefficient & $p$ value & $\overline{\beta \text { coefficient }}$ & $p$ value \\
\hline Age of offspring (years) & 0.0110 & 0.0001 & 0.0106 & 0.0001 \\
\hline DR in first parent (DR vs D) & 0.0596 & 0.004 & 0.0660 & 0.013 \\
\hline $\mathrm{D}$ in 2 nd parent (D vs ND) & 0.0366 & 0.105 & 0.0385 & 0.182 \\
\hline Age of onset of parental diabetes (years) & -0.0035 & 0.001 & -0.0032 & 0.022 \\
\hline
\end{tabular}

$\mathrm{DR}$, diabetic with renal disease; $\mathrm{D}$, diabetic, without renal disease as defined in Table 1 ; age of offspring was the age at time of occurrence of the maximum 2-h plasma glucose. Age at onset of diabetes was that of the diabetic parent (or younger of the two ages of onset if both parents diabetic). Sex was origi-

conditional regression model which accounted for the interdependence of the within family observations [21] (Table 4, right). Controlled for the same variables listed above, the regression coefficients were quite similar to those of the conventional regression model, and the presence of parental diabetic renal disease was again associated significantly $(p=0.01)$ with higher maximum levels of 2-h plasma glucose in the offspring relative to that of parental diabetes alone (Table 4, right).

Adjusted maximum plasma glucose concentrations determined by the conditional regression mod$\mathrm{el}$, in offspring aged 20 years, for the four parental combinations, by age at onset of parental diabetes, are shown in Figure 2. An earlier age at onset of parental diabetes was associated with the highest plasma glucose concentrations in the offspring, but the additional effect of parental diabetic renal disease to that of diabetes alone was also evident.

\section{Discussion}

The high prevalence of both NIDDM [13] and diabetic nephropathy $[19,22]$ in the Pima Indians, and the detailed follow-up of the population for a prolonged period, have allowed the prevalence of diabetes in offspring to be examined by defined combinations of parental variables. The ascertainment of renal disease, both by routine biennial examination and by active surveillance of all subjects receiving dialysis or nally included in the model but was removed as it had a nonsignificant effect. The conditional regression model controlled for intrasibship correlation using SAGE program REGC [21]. For definitions of terms see text

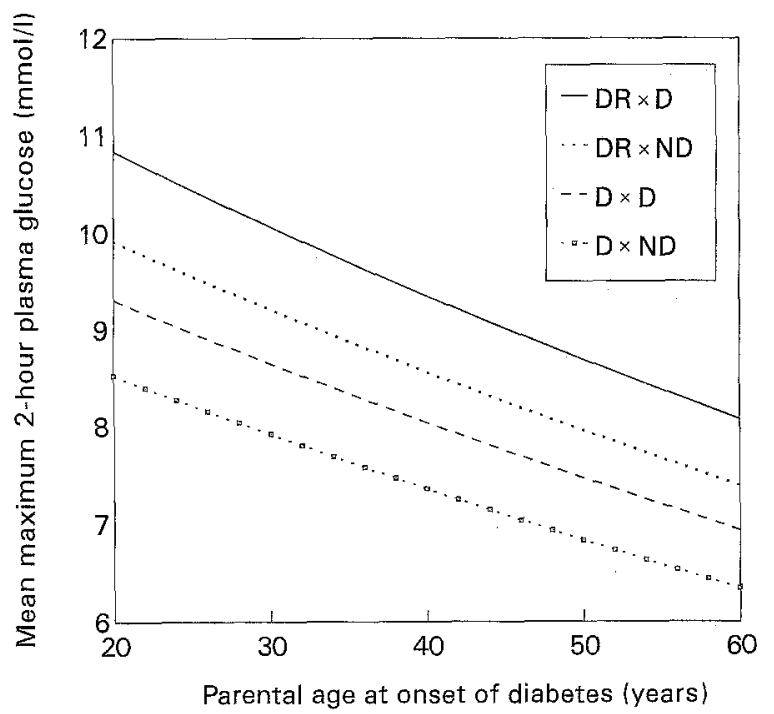

Fig. 2. Age-adjusted geometric mean of maximum 2-h plasma glucose values in offspring aged 20 years by combination of parental categories and increasing age at onset of parental diabetes calculated from the conditional regression model. For definition of parental categories see Footnote to Table 1

specialist renal care in the community, provides for an accurate assessment of renal status.

The prevalence of nephropathy is related to duration of diabetes in this population, and conceivably, given time, the majority of diabetic patients might develop this complication. This was the reason for our 
choice of a specific duration of diabetes (15 years) within which those patients who had not developed nephropathy were considered at lower risk of nephropathy. Our definition of nephropathy by the degree of proteinuria ( $\mathrm{pc}$ ratio $\geq 1.0$ ) was to ensure a level which was predictive of subsequent ESRD. However, the findings were similar when nephropathy was defined as a pc ratio of $\geq 0.5$. It would be interesting to see if similar results would be obtained based on microalbuminuria, assays for which were not available when most of the parental data were collected. Using the defined parental types we were also able to directly compare the relative risk for disease in the various offspring groups, an analysis which would have been difficult treating duration of diabetes as a continuous variable, because the value is undefined in the non-diabetic subjects.

The presence of parental diabetic renal disease was associated with 2.5 times the odds of diabetes in the offspring relative to parental diabetes alone. This effect was independent of age at onset of parental diabetes and was particularly evident among those offspring under the age of 35 years. Parental diabetic renal disease was also independently associated with the severity of diabetes, as represented by plasma glucose as a continuous variable in the offspring.

If the genetic load hypothesis is correct, the greatest prevalence of diabetes should be seen in the offspring of two DR parents. This was the case among offspring older than 35 years of age, and among younger offspring, the prevalence of diabetes was similar between offspring of $\mathrm{DR} \times \mathrm{DR}$ and $\mathrm{DR} \times \mathrm{D}$ parents.

A possible concern is whether these results could be biased by more complete ascertainment of diabetes in offspring of those with diabetes and renal disease. This did not appear to be the case however as among offspring of parents with renal disease, there were no statistically significant differences either in the proportion who had ever had a biennial examination or in the number of examinations preceding the diagnosis of diabetes (data not shown).

The reasons for the observed familial clustering of diabetes and renal disease are not clear and might be explained by several genetic and environmental mechanisms. At the very least, our findings suggest that the factors responsible for the familial aggregation of NIDDM are associated with those responsible for the familial aggregation of diabetic nephropathy. If these factors are genetic, then diabetes and nephropathy may be inherited through the same gene or genes. The results would therefore be compatible with the hypothesis that a greater load of diabetes susceptibility genes or a set of environmental factors correlated within families increases the risk of renal complications in the parents and of transmission of diabetes susceptibility to the offspring. Whether this hypothesised genetic load results from homozygosity at a single locus or from susceptibility alleles at several loci remains speculative without knowledge of a specific diabetes susceptibility gene or genes in this population. The potential familial environmental factors have not been investigated in detail, and the variables examined do not account for all the variation in the prevalence of diabetes.

A variable age at onset of diabetes (which of itself may be in part genetically determined) is a complicating factor in any analysis of families and evidence of the familial transmission of this characteristic has been demonstrated previously in this population [5]. In the present study however, the effect of parental diabetic nephropathy on the presence of diabetes in the offspring was independent of parental age at onset of NIDDM. Thus, the present findings do not simply reflect transmission of susceptibility to diabetes with an early age of onset. However, an earlier age at onset of parental diabetes was also associated with plasma glucose in the offspring (Fig.2), suggesting that both the age at diabetes onset and the presence of renal disease in the parents have an impact, not only on the presence of diabetes, but also on the degree of hyperglycaemia in the offspring.

In summary, the present results provide support for parental diabetic nephropathy, independent of age at onset of parental diabetes, conferring an increased risk for diabetes in the offspring. The findings are consistent with clustering of environmental risk factors in these families or with the hypothesis that the same genetic locus (or loci) determine susceptibility to both diabetes and renal disease; i. e., parents with diabetes and renal disease have a greater genetic load which increases the risk of transmitting diabetes to the offspring.

Acknowledgements. We wish to thank the members of the Gila River Indian Community who participated in the study, the laboratory personnel who performed the laboratory tests, and Dr. R. C. Elston for advice. Special thanks are also due to Ms. V. Andre R.N. for help with abstraction of clinical data and to Drs. R. G. Nelson, D. A. Reichert and the staff of the Data Coordinating Center of the Gila River Indian Community and the Native American Dialysis Center, Sacaton, Arizona, for providing details of patients receiving renal supervision and dialysis. Some of the analyses used in this paper were performed using the program package S.A.G.E., which is supported by a U.S. Public Health Service Resource Grant (1 P41 RR03655) from the Division of Research Resources.

\section{References}

1. Rimoin DL (1972) Inheritance in diabetes mellitus. Med Clin N Am 55: 807-819

2. Köbberling J, Tillil H, Lorenz HJ (1985) Genetics of type 2A- and type 2B-diabetes mellitus. Diabetes Res Clin Pract ii: [Suppl] 1: S311 (Abstract)

3. Lee ET, Anderson PS, Bryan J, Bahr C, Coniglione T, Cleves M (1985) Diabetes, parental diabetes and obesity in Oklahoma Indians. Diabetes Care 8: 107-113 
4. Viswanathan M, Mohan V, Snehalatha C, Ramachandran A (1985) High prevalence of type 2 (non-insulin-dependent) diabetes among offspring of conjugal type 2 diabetic parents in India. Diabetologia 28: 907-910

5. Knowler WC, Pettitt DJ, Saad MF, Bennett PH (1990) Diabetes mellitus in the Pima Indians: incidence, risk factors and pathogenesis. Diabetes Metab Rev 6: 1-27

6. Knowler WC, Pettitt DJ, Savage PJ, Bennett PH (1981) Diabetes incidence in Pima Indians: contributions of obesity and parental diabetes. Am J Epidemiol 113: 144-156

7. Seaquist ER, Goetz FC, Rich S, Barbosa J (1989) Familial clustering of diabetic kidney disease: evidence for genetic susceptibility to diabetic nephropathy. New Engl J Med 320: 1161-1165

8. Pettitt DJ, Saad MF, Bennett PH, Nelson RG, Knowler WC (1990) Familial predisposition to renal disease in two generations of Pima Indians with type 2 (non-insulin-dependent) diabetes mellitus. Diabetologia 33: 438-443

9. Knowler WC, Pettitt DJ, Bennett PH, Williams RC (1983) Diabetes mellitus in the Pima Indians: genetic and evolutionary considerations. Am J Phys Anthropol 62: 107-114

10. Knowler WC, Savage PJ, Nagulesparan M et al. (1982) Obesity, insulin resistance and diabetes mellitus in the Pima Indians. In: Köbberling JM, Tattersall R (eds) The genetics of diabetes mellitus. Serono Symposium No. 47 Academic Press, London, pp 243-250

11. Knowler WC, Pettitt DJ, Lillioja S, Nelson RG (1988) Genetic and environmental factors in the development of diabetes mellitus in the Pima Indians. In: Smith U, Eriksson S, Lindgärde $F$ (eds) Genetic susceptibility to environmental factors - a challenge for public intervention. Almqvist and Wiksell International, Stockholm pp 67-84

12. Knowler WC, Bennett PH, Hamman RF, Miller M (1978) Diabetes incidence and prevalence in Pima Indians: 19- fold greater incidence than in Rochester Minnesota. Am J Epidemiol 108: 497-505

13. Bennett PH, Burch TA, Miller M (1971) Diabetes mellitus in American (Pima) Indians. Lancet II: 825-828

14. WHO Study Group. (1985) Diabetes mellitus. World Health Organization, Geneva pp 9-17 (Tech Rep Ser 727)

15. Shersky MC, Stafford DD (1923) A clinical method for the estimation of protein in urine and other body fluids. Arch Intern Med 32: 222-225

16. Chasson AL, Grady HJ, Stanley MA (1961) Determination of creatinine by means of automatic chemical analysis. Am J Clin Pathol 35: 83-88

17. Ginsberg JM, Chang BS, Matarese RA, Garella S (1983) Use of single voided urine samples to estimate quantitative proteinuria. New Engl J Med 309: 1543-1546

18. Shaw AB, Risdon P, Lewis-Jackson JD (1983) Protein creatinine index and Albustix in assessment of proteinuria. BMJ 287: 929-932

19. Nelson RG, Newman JM, Knowler WC et al. (1988) Incidence of end-stage renal disease in type 2 (non-insulin-dependent) diabetes mellitus in Pima Indians. Diabetologia 31: 730-736

20. Kleinbaum DG, Kupper LL, Morgenstern H (1982) Epidemiologic research: principles and quantitative methods. Van Nostrand Reinhold, New York, Berkshire, Melbourne, Ontario, 419-446

21. S. A.G.E. Statistical Analysis for Genetic Epidemiology, Release 2.1. (1992) Computer program package. Department of Biometry and Genetics, LSU Medical Center, New Orleans

22. Kunzelman CL, Knowler WC, Pettitt DI, Bennett PH (1989) Incidence of proteinuria in type 2 diabetes mellitus in the Pima Indians. Kidney Int 35: 681-687 